\title{
Covid-19: Why Virtual Learning Becomes a Pedagogical Acceptance Model in Africa
}

\author{
https://doi.org/10.3991/ijet.v17i01.23567 \\ Nubi James ${ }^{1}$, Olufunke Rebecca Vincent ${ }^{1}$, Noah Oluwatobi Akande ${ }^{2(\bowtie)}$, \\ Ayodeji Samuel Makinde ${ }^{3}$ \\ ${ }^{1}$ Department of Computer Science, Federal University of Agriculture, Abeokuta, Nigeria \\ ${ }^{2}$ Department of Computer Science, Landmark University, Kwara State, Nigeria \\ ${ }^{3}$ Department of Computer Science, Edo University, Iyamho, Nigeria \\ akande.noah@lmu.edu.ng
}

\begin{abstract}
The outbreak of coronavirus pandemic has led to different regulations and changed the usual way of doing things. Considering the level of technology in Africa society before the outbreak of the epidemic many activities, including classroom teaching and learning were affected. This paper examines virtual learning as an unavoidable pedagogical model for learning during the COVID-19 pandemic. A cross-sectional study was conducted by adopting the Technology Acceptance Model. Data were obtained from an online survey of 543 respondents and analyzed. Regression of Partial Least Squares (PLS) was used for modeling and hypothesis testing. The results revealed that perceived usefulness, perceived ease of use, regulatory compliance, and implementation context significantly affect educators' and learners' attitudes towards adopting virtual learning for learning. Subsequently, regulatory compliance had the most substantial influence on educators' and learners' attitudes towards adopting virtual learning for learning during the COVID-19 outbreak. This study established that the adoption of virtual learning has enhanced learning during the coronavirus pandemic lockdown, and the process would also continue after the pandemic. Virtual learning has provided the classroom experience for learners and educators.
\end{abstract}

Keywords—coronavirus, technology acceptance model, e-learning, teaching and learning

\section{$1 \quad$ Introduction}

\subsection{Applying the styles to an existing paper}

The global health pandemic, COVID-19, remains the world's greatest threat since World War II, which has dramatically changed the planet by changing the world, splitting it into two for those with digital consumer access and those without. Coronavirus disease 2019 (COVID-19) has killed millions of people worldwide until now. Data about the number of tests administered, positive cases, discharge, and deaths 
continues to increase hourly since January 2020 (World Health Organization, WHO, 2020a; Guo et al., 2020. Africa has recorded 251,866 deaths in 55 (55) countries, including 1,14308 Recoveries in 55 African countries, accounting for approximately 3.2 per cent of the total documented incidences globally as of 16 June 2020 [1]. Of those cases, 63 percent are represented in 5 of these African countries. Amongst these are South Africa (34\%), Egypt (16\%), Nigeria (6\%), Ghana (4\%) and Cameroon (3 percent). There are already growing concerns about the strain on health-care systems globally and are likely to worsen significantly. The ever-increasing morbidity and mortality resulting from COVID-19, along with the economic impacts, is the most significant setback. The WHO report revealed that the mortality rate was between 3 to 4 percent [2]; however, the statistics on mortality appeared to be underestimated [4].

The typical day-to-day living behaviours are determined by what is valued about the perceived danger. The state of lockdown in many countries worldwide, which mainly contributed to the global economy, has added to the marketing, services, and manufacturing of goods being halted. This has contributed to a fracture in global supply chains and has, thus, violently impacted the global economy [4][5][6]. Globally, transportation, entertainment, sports activities, Military training, and education have been affected. The transportation sector has stopped working due to lock-downs in different countries. Besides, importation and exportation of goods and materials have also been adversely affected. Most employees at the company are required to work from home. The educational sector had to have an automatic break, where learners were sent home with short notice. Thus, learning in the classroom has been obstructed; the confusion and delay of examination is also a stressor for the young minds. Traditional teaching and learning have become a challenge in Africa, as it has become necessary to observe social distance to achieve victory over this pandemic. Sequel to this, access to virtual communication platforms and immersive applications became an advantage over face-to-face learning. Since many learners can be engaged with ample learning resources, multiple chat functions of application for live quizzes and polls provide valuable learning modalities [7] Virtual learning technologies are now being used for formal education purposes, it is now cleared that the features and theories suggested by the conception of virtual learning can be quite useful for learning. Continuous technological improvement has made interactive and virtual learning much cheaper, more comfortable, and more enjoyable.

This paper presents virtual learning as an excellent resource and compliment of face-to-face teaching and learning. This examines the adoption of virtual education during the period of the COVID-19 pandemic. The study considers virtual learning a unique need and concern for educators and learners during the COVID-19 epidemic. The review uses the Technology Acceptance Model (TAM) for the analysis. In its pure form in an open simulator environment, virtual learning allows multiple users to interact and communicate by sharing information such as text, audio, image, and video [8][9][10] Virtual learning represents a user-friendly application with a beneficial interface that could be enabling students to feel they are in-charge by merely engaging and disengaging from the computer screen. This helps students to connect, communicate, and collaborate efficiently in an integrated manner [11]. As virtual learning is used as an instructional model of learning and teaching, it increases stu- 
dents' curiosity through their ability to involve them in the circumstances otherwise challenging to encounter and to use interactive resources presented directly as virtual objects to the students. By building a virtual environment through which students can learn about the natural world experientially in the past, present, or future, Virtual learning provides an outstanding learning experience that transcends traditional boundaries as a place and space [13]. This study of virtual learning is related to the educational sector. The paper is organized as follows. Section 2 presents the relevant related model for Technology Acceptance, while section 3 describes the methodology. In section 4, analysis, interpretations, and results are presented. Section 5 gives the discussion, while Section 6 concludes the paper.

\section{$2 \quad$ Related models}

Many models have emerged from research concerning the acceptance of users and the intention to use new technology. The first technology acceptance theory was the theory of reasoned action [14]; an extension was the theory of planned actions (TPB), which specifies that attitudes and social norms influence behavioral intent, which in turn influences actual behavior [15]. TAM / TAM2 is used extensively in the information science (IS) field to explain how IT tools are accepted. The theory of reasoned action defined the assessment of the Technology Acceptance Model (TAM) as a collection of standardized beliefs that extend across a variety of information technology (IT) resources with two primary essential determinants of intent: ease of use and usefulness [16]. TAM has been used several in different dimensions to measure the extent of acceptance of new technology. Diop et al. applied TAM to understand travelers' acceptance of Advanced Traveler Information Systems (ATIS) to mitigate traffic congestion and improve network performance. This study adopted an extended Technology Acceptance Model (TAM) to predict and explain road users' intention to use the Variable Message Sign (VMS) information [19]. Using conventional parsimonious TAM constructs (perceived usefulness, perceived ease of use, and behavioral intention), the model examined the effects of attitude towards route diversion, familiarity with the road network, and information quality on road users' acceptance of VMS. The study showed that travelers' attitudes towards route diversion positively affected perceived usefulness and intention to use VMS. The information system directly impacted perceived usefulness, perceived ease of use, and attitude towards route diversion. In another perspective, Hoong et al. also used TAM at different levels to examine the acceptance of eCommerce, Mobile, and ERP technologies [18]. The study considers the role of a knowledge worker who works in Multimedia Super Corridor (MSC)-status organizations in Malaysia on their behavioural intention to use knowledge sharing tools (KS tools) in their day-to-day tasks. The behavioural intention on the acceptance of KS tools was hypothesized in the Affective Technology Acceptance.

Zainab et al. also considered the role of perceived cost, computer self-efficacy, and the Technology Acceptance Model (TAM) constructs in e-training adoption in the Nigerian civil service. The study used a framework that included perceived cost, 
computer self-efficacy, and TAM constructs (Perceived Usefulness (PU) and Perceived Ease of Use (PEOU)) was tested on 450 heads of departments. Scales on perceived cost, computer self-efficacy, PU, and PEOU developed by previous studies were modified and used [19]. The findings of the study showed that perceived cost had a significant effect on e-training adoption. It was discovered that computer selfefficacy was statistically insignificant through PEOU. Besides, PEOU had an indirect effect through PU, and it showed that only PU of the TAM constructs indicated strong predictive strength in e-training adoption. Liebenberg et al. examined the acceptance of digital technology among university students. The study determined the applicability of the Unified Theory of Acceptance and Use of Technology (UTAUT) model within a South African higher education setting and to clarified the factors that were influencing students' intentions to make use of two digital technologies: an eBook and SLMS. Effort Expectancy (EfEx), Facilitating Conditions (FC), Self-Efficacy (SE), Anxiety (Anx), Attitude towards using technology (ATT), and Behavioural intention (BI) were analysed [20]. The statistical analysis was used to develop and assess a model of behavioural intention factors (BI). Structural equation modeling was used, and the goodness-of-fit test indicated that the data supported the model. Some of the factors, such as EfEx, showed high practically significant relationships with BI.

In this study, we study the recent acceptance of virtual learning as the only option during the COVID-19 pandemic lockdown. The proposed research uses a modified TAM called COVID-phobia TAM to analyse some construct relation to new technology for learning and examined the relationship among the constructs.

\section{$3 \quad$ Methodology}

This study examines the effect of the coronavirus on the educational sector. The study considers e-learning as a form of virtual learning in teaching and learning. We design a questionnaire for secondary school and tertiary institution students in Nigeria and their teachers to analyze how the lockdown has affected teaching and learning and how society eventually adopted virtual learning. This research was undertaken using a mixed-method approach that incorporated qualitative and quantitative elements by delivering questionnaires into surveys. The survey was designed to evaluate educators' and learners' views on digital technology's importance during the lockdown period. In the current COVID-19 pandemic situation, the techniques and hypotheses implied by virtual learning development are beneficial in learning. They are used effectively to solve the problems of physical contact during the pandemic lockdown. The research questions were planned to achieve the following as follows:

- RQ1: What is the pertinent relationship between perceived usefulness and attitude of educators and learners towards adopting virtual learning for learning during the global pandemic lockdown?

- RQ2: What is the pertinent relationship between perceived ease of use and educators' attitude towards adopting virtual learning for learning during the global pandemic lockdown? 
- RQ3: What is the significance between educators' and learners' regulatory compliance and attitude towards adopting virtual learning for learning during the global pandemic lockdown?

- RQ4: What is the significance between educators' and learners' implementation context and attitude towards adopting virtual learning for learning during the global pandemic lockdown?

- RQ5: What is the congruence between educators' attitude and behavioral intention to adopt virtual learning for learning during the global pandemic lockdown?

\subsection{The Technology Acceptance Model (TAM)}

The Technology Acceptance Model (TAM) has been one of the essential models used to adapt and accept new technology. It is used for predicting the intention to use a particular technology and its adoption and acceptance [21] [22]. In TAM, the social aim of using another innovation is determined by the individuals' state of mind towards using this innovation [23]. The fundamental principle of the underlying theory of psychology, called Theory of Reasoned Act, is that action is affected by a person's attitude toward this action, by an individual's confidence in the outcome if he adopts it, and by an appraisal of behavior [14] [24]. TAM recognizes the thoughtfulness of a man's state of mind for the use of another invention. The key determinant is how it profit, which refers to how much a man feels that using the latest technology will improve the output.

The fear of contacting the coronavirus has increased the acceptance and use of virtual learning models within the last few months; Technology Acceptance Model is used to examine and analyze how users accept and adopt the use of e-learning. Specifically, the study investigates the impact of e-learning technology on teaching and learning during the Coronavirus outbreak. The model is implemented using a structured questionnaire that provides the answers on a Likert scale, from strongly disagree to strongly agree. Figure 1 shows two main factors in evaluating acceptance: the independent variables, which are external, and the dependent variable. The selfemployed are perceived utility, perceived ease of use, regulatory enforcement, implementation context, while the dependent variables are the attitude to use, behavioral purpose, and actual usage.

Perceived Usefulness (PU). Usefulness is regarded as the observation that the person making use of the innovation will improve in performance. Perceived Usefulness is the degree to which a person assumes their job performance will be enhanced using a specific application or program. This demonstrates the user's recognition that virtual learning technologies can improve active learning. Users see how essential the apps help carry out their tasks and how effective the virtual learning applies to education when educators and learners may meet in a virtual classroom. PU is the most critical determinant of educators' behavioral intention to embrace technology from past studies [25] [26]. When educators and learners believe that virtual technology will improve their learning, the decision to incorporate technology would be approved.

Perceived Ease of Use (PEU). Ease of Use is defined as the user's expectation that the invention's implementation would be effortless. Perceived ease of use is the de- 
gree to which an individual assumes that it would require little or less effort to use a particular application. It means that using a specific technology would be free of physical and mental stress [27]. In this case, it can be assumed that virtual learning will at least involve no much physical effort or stress. It refers to how convenient virtual learning will be to educators and learners. The user may agree that a given innovation is helpful, but the user may find that innovation is challenging to use; thus, it is essential to know whether it is effort-free (Teo, 2009). The user's perception of ease of use is an indicator of the quality required to use a technology or the degree to which a user recognizes the effortlessness and smoothness of using a particular invention.

Regulatory compliance. Regulatory compliance is an independent variable added in the proposed model since people are left with no option but to comply with the anti-coronavirus rules by adopting technology innovations in different aspects of their lives. Regulatory enforcement defines the goal of ensuring that they are aware of and take measures to comply with relevant rules, policies, and regulations. Due to the increasing number of cases and the high death rate, the government created a social distance rule. Now, there is a need to enforce a high rate of compliance, which initiated the lockdown. In this case, we are interested in how this affected the educational section. The need for operational transparency has made organizations adopt consolidated and harmonized sets of compliance controls.

Implementation context. The implementation context also determines if the user will adopt the technology. The adoption of technology was done by analyzing the cost factor, training, and social influence. The cost factor of the adoption has to do with the investment cost of IT. We study the relationship between the behavioural intention to use virtual learning and the perceived cost. Another factor considered is the training of educators and learners.

Attitude Towards Use (ATU). Attitude is described as the positive or negative feeling of a person performing the target action. Consciousness goes hand in hand with attitude, and a positive attitude toward ICT is accepted as a necessary condition for successful implementation. Performance in e-learning is influenced by various factors, including users' attitudes towards e-learning and their satisfaction with technology during the teaching/learning experience [29]. Research has also shown that awareness of the educators' technology attitude and their impact on their job helps create more suitable teaching technology training programmes.

Behavioural intention. The intention describes how people are willing to try and how much determination they plan to perform a behaviour. Behavioral Purpose (BI) is subjective to an individual's probability of doing some routines. Behavioural intention is highly influenced by users' attitude to use the technology [29] [30].

Actual use. The actual use of technology is determined by the behavioural intention of the user to adopt a technology. The user's behavioural intention influences it if he/she uses the technology for it is designed [31]. 


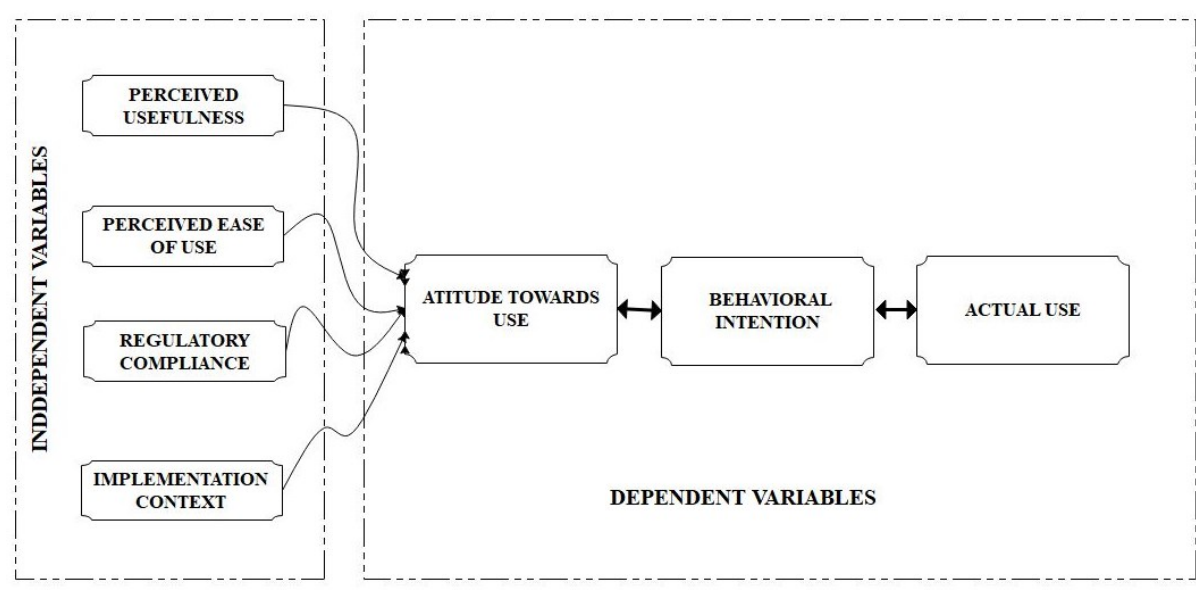

Fig. 1. A Technology acceptance model for E-learning

\section{$4 \quad$ Results and discussion}

This section provides a detailed analysis and interpretations of the results achieved in this research.

\subsection{Results analysis}

In this study, we design a structured questionnaire to assess teachers' and learners' perceptions of the use of e-learning technologies for learning during COVID-19 lockdown. The questionnaire was developed to follow the Likert scale rule between 1 to 5 . The survey respondents were 543. The research variables consist of 7 variables. Four (4) variables were independent, and others three (3) as dependent variables. The independent variables are perceived usefulness, perceived ease of use, regulatory compliance, and implementation context, while the dependent variables are attitude towards use, behavioural intention, and actual use. The experimental survey was carried out between May and June 2020, which helped to evaluate the validity and phrasing at the exact time when people were at home during the pick of the lockdown. The educators' mean age is 58.8, with a standard deviation (SD), 10.74, and an age range between 30 and 75 . The leaners' mean age is 28.45 , with a standard deviation (SD), 8.8 , and the age ranges from 10 to 55 years. Out of the respondents, learners were 413 , while educators were 1130 , making $76.0 \%$ and $24.0 \%$, respectively. Figure 2 shows the age distribution of the respondents. Most of the participants are of age 26-35. 


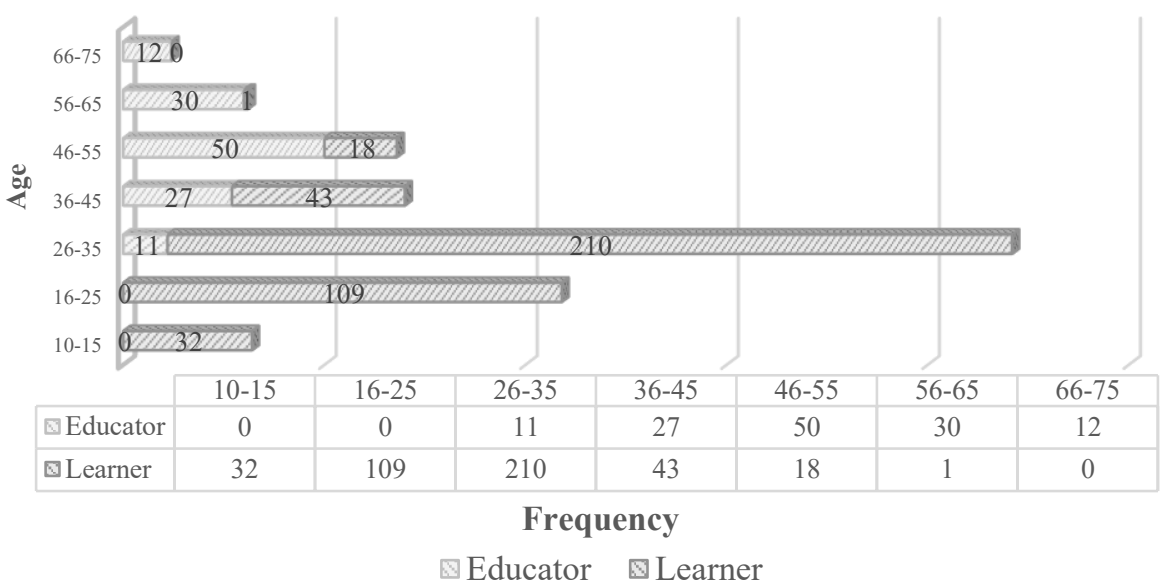

Fig. 2. Age distribution of the respondents

The survey tested the extent of the learners' and teachers' exposure to different virtual learning platforms. Table 1 presents the analysis of the level of exposure to the virtual learning platforms before and during the lockdown. Table 2 shows the constructs' dialogue to understand the extend of adoption between the educators and the learners.

The composite reliability and Average Variance Extracted (AVE) were computed to determine the constructs' reliability and validity. As shown in Table 3, allcomposite strength measures ranged from 0.694 to 0.951 ; this indicates higher reliability since the composite reliability has to be greater than 0.6 . Thus, the proposed model meets the reliability recommendation for the item. When different elements are used to test the same object, convergent validity is displayed, and there is a clear correlation between the scores from the various items. All factor loadings are significant and greater than 0.5 to ensure convergent validity. Table 3 indicates an extremely significant factor loading of all products $(\mathrm{p}<0.001)$ and higher than 0.5 . Discriminant validity assesses whether the definitions are properly distinguishable from each other. Discriminant validity shows if the AVE's square root for a build is more significant than its correlations with other buildings.

The vast variety of virtual meeting platforms has created a new level of educational convenience where students can participate on a forum in which online connectivity is easily integrated within the time constraints of daily working days. Virtual education has created a teaching platform that is readily available and can be used conveniently. The clustered bar chart in Figure 3 compares the awareness and usage of virtual learning flatforms like WhatsApp, Telegram, Skype, Zoom, educadium, Google Classroom, You tube, Microsoft, Teams, Google, Meet, Loom, Teachable, Edmodo, Turnitin, Schology and Quizlet. 
Table 1. Survey Analysis

\begin{tabular}{|c|c|c|c|}
\hline Criteria & Learners & Educators & Total Respondents (\%) \\
\hline People & 413 & 130 & $543(100.0 \%)$ \\
\hline High level of IT & 328 & 69 & $397(73.1 \%)$ \\
\hline \multicolumn{4}{|c|}{ E-learning Platform(s) you have used before lockdown } \\
\hline WhatsApp & 380 & 118 & $498(91.7 \%)$ \\
\hline Telegram & 186 & 87 & $273(50.1 \%)$ \\
\hline Skype & 169 & 89 & $258(47.5 \%)$ \\
\hline Zoom & 204 & 102 & $306(56.4 \%)$ \\
\hline Google Classroom & 198 & 82 & $280(51.6 \%)$ \\
\hline You tube & 315 & 121 & $436(80.1 \%)$ \\
\hline Microsoft Teams & 165 & 74 & $239(44.0 \%)$ \\
\hline Google Meet & 180 & 70 & $250(46.0 \%)$ \\
\hline \multicolumn{4}{|c|}{ E-learning Platform(s) you have used during the lockdown } \\
\hline WhatsApp & 411 & 130 & $541(99.6 \%)$ \\
\hline Telegram & 381 & 112 & $493(90.8 \%)$ \\
\hline Skype & 304 & 118 & $422(77.7 \%)$ \\
\hline Zoom & 385 & 129 & $514(94.7 \%)$ \\
\hline Educadium & 176 & 34 & $210(38.7 \%)$ \\
\hline Google Classroom & 345 & 122 & $467(80.0 \%)$ \\
\hline You tube & 396 & 128 & $524(96.5 \%)$ \\
\hline Microsoft Teams & 320 & 116 & $436(80.1 \%)$ \\
\hline Google Meet & 368 & 104 & $472(86.9 \%)$ \\
\hline Loom & 211 & 43 & $254(56.1 \%)$ \\
\hline Teachable & 109 & 35 & $144(26.5 \%)$ \\
\hline Edmodo & 42 & 5 & $47(8.7 \%)$ \\
\hline Turnitin & 398 & 129 & $527(97.1 \%)$ \\
\hline Schology & 150 & 31 & 181(33.3\%) \\
\hline Quizlet & 112 & 60 & $172(31.7 \%)$ \\
\hline
\end{tabular}

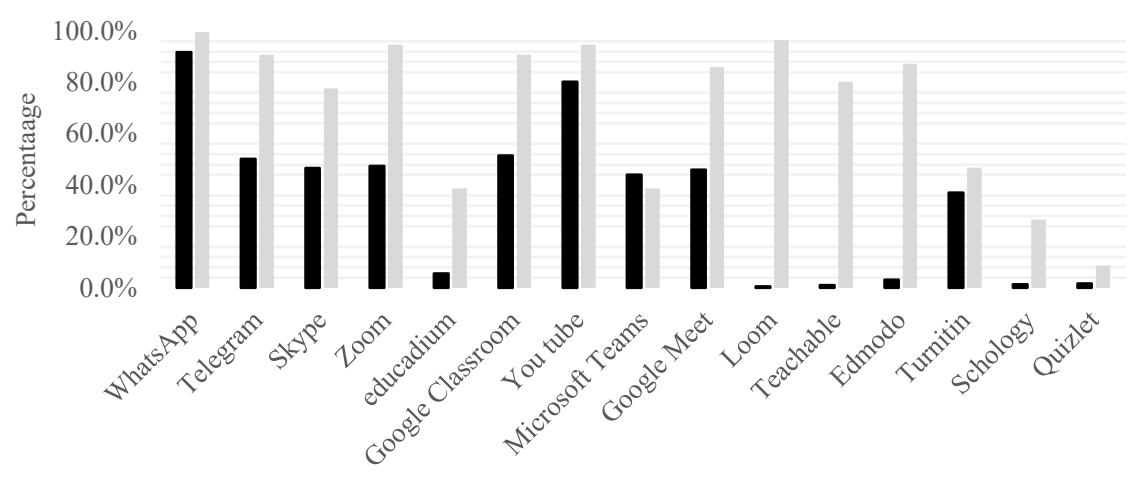

- BEFORE COVID-19 DURING COVID-19

Fig. 3. Percentage of adoption before Covid-19 and during Covid-19 
Paper-Covid-19: Why Virtual Learning Becomes a Pedagogical Acceptance Model in Africa

Table 2. Attitudinal Test of Learners and Educators

\begin{tabular}{|c|c|c|}
\hline Construct & Variable & Dialogue \\
\hline \multirow{4}{*}{ Perceived Usefulness } & Q-PU1 & The e-learning applications are very useful \\
\hline & Q-PU2 & The e-learning app helps me in learning fast \\
\hline & Q-PU3 & The e-learning environment is accessible for teaching \\
\hline & Q-PU4 & The teaching materials are very useful for me \\
\hline \multirow{4}{*}{ Perceived Ease of Use } & Q-PEU1 & The e-learning platform is easy to access \\
\hline & Q-PEU2 & The platform is easy to install \\
\hline & Q-PEU3 & Information given is easy to understand \\
\hline & Q-PEU4 & Learners enjoy the \\
\hline \multirow{4}{*}{ Regulatory Compliance } & Q-RC1 & There are only a few protocols to observe \\
\hline & Q-RC2 & Few interesting steps are needed \\
\hline & Q-RC3 & The interface is interesting to interact with \\
\hline & Q-RC4 & I make use of this platform because I have no alternative \\
\hline \multirow{4}{*}{$\begin{array}{l}\text { Implementation Con- } \\
\text { text of e-learning }\end{array}$} & Q-IC1 & I found it easy to adjust to e-learning \\
\hline & Q-IC2 & I understand the operation of e-learning \\
\hline & Q-IC3 & I found it easy to adjust form one platform to another \\
\hline & Q-IC4 & E-platform implementation is easy for me \\
\hline \multirow{4}{*}{$\begin{array}{l}\text { Behavioural Intention } \\
\text { to Use of e-learning }\end{array}$} & Q-BI1 & I would still prefer e-learning after lockdown \\
\hline & Q-BI2 & I intend to join e-learning for my class \\
\hline & Q-BI3 & I plan to participate in the e-learning class \\
\hline & Q-BI4 & I appreciate the e-learning platform \\
\hline \multirow{4}{*}{$\begin{array}{l}\text { Attitude Towards the } \\
\text { Use of e-learning }\end{array}$} & Q-ATU1 & I enjoy doing e-learning \\
\hline & Q-ATU2 & I am willing to use e-learning platforms \\
\hline & Q-ATU3 & I can easily adjust to the e-learning platform \\
\hline & Q-ATU4 & using e-learning is interesting for me \\
\hline
\end{tabular}

Table 3 shows that the measurement model meets the discriminating validity requirement. In Table 3, AVE represents Average Variance Extracted, $\lambda$ means Factor Loadings, $\sum$ represents Error Variance, while CR means Composite Reliability. The fit indexes assess just how well the measurement model represents the sample. The Chi-square p-value was $0.000(\ddot{y} 2=462.777, \mathrm{df}=126)$. The approximate Root Mean Square Error (RMSEA) and the Standardized Root Mean Square Residual (SRMR) were 0.054 and 0.046. An RMSEA is less than 0.07, and an SRMR less than 0.08 is considered an appropriate fit signal. Therefore, the suggested range was within the SRMR and RMSEA. The Comparative Fit Index (CFI), the Normed-Fit Index (NFI), and the Tucker-Lewis Index (TLI) were 0.934, 0.958, and 0.933, respectively. 
Table 3. Validity and Reliability of the measurement of the Covidphobia TAM.

\begin{tabular}{|c|c|c|c|c|c|c|c|}
\hline Variables & Questions & $\lambda$ & $\lambda 2$ & $\varepsilon$ & AVE & P-Value & CR \\
\hline \multirow{4}{*}{ Perceived Usefulness } & Q-PU1 & 0.817 & 0.667 & 0.3325 & \multirow{4}{*}{0.695} & $<0.001$ & \multirow{4}{*}{0.901} \\
\hline & Q-PU2 & 0.804 & 0.646 & 0.3536 & & $<0.001$ & \\
\hline & Q-PU3 & 0.811 & 0.658 & 0.3423 & & $<0.001$ & \\
\hline & Q-PU4 & 0.898 & 0.806 & 0.1936 & & $<0.001$ & \\
\hline \multirow{4}{*}{ Perceived Ease of Use } & Q-PEU1 & 0.729 & 0.531 & 0.4686 & \multirow{4}{*}{0.619} & $<0.001$ & \multirow{4}{*}{0.866} \\
\hline & Q-PEU2 & 0.901 & 0.812 & 0.1882 & & $<0.001$ & \\
\hline & Q-PEU3 & 0.702 & 0.493 & 0.5072 & & $<0.001$ & \\
\hline & Q-PEU4 & 0.801 & 0.642 & 0.3584 & & $<0.001$ & \\
\hline \multirow{4}{*}{ Regulatory Compliance } & Q-RC1 & 0.992 & 0.984 & 0.0159 & \multirow{4}{*}{0.831} & $<0.001$ & \multirow{4}{*}{0.951} \\
\hline & Q-RC2 & 0.921 & 0.848 & 0.1518 & & $<0.001$ & \\
\hline & Q-RC3 & 0.801 & 0.642 & 0.3584 & & $<0.001$ & \\
\hline & Q-RC4 & 0.922 & 0.850 & 0.1499 & & $<0.001$ & \\
\hline \multirow{4}{*}{ Implementation Context of e-learning } & Q-IC1 & 0.567 & 0.321 & 0.6785 & \multirow{4}{*}{0.367} & $<0.001$ & \multirow{4}{*}{0.694} \\
\hline & Q-IC2 & 0.722 & 0.521 & 0.4787 & & $<0.001$ & \\
\hline & Q-IC3 & 0.611 & 0.373 & 0.6267 & & $<0.001$ & \\
\hline & Q-IC4 & 0.500 & 0.250 & 0.7500 & & $<0.001$ & \\
\hline \multirow{4}{*}{ Behavioural Intention to use e-learning } & Q-BI1 & 0.777 & 0.604 & 0.3963 & \multirow{4}{*}{0.636} & $<0.001$ & \multirow{4}{*}{0.872} \\
\hline & Q-BI2 & 0.603 & 0.364 & 0.6364 & & $<0.001$ & \\
\hline & Q-BI3 & 0.782 & 0.612 & 0.3885 & & $<0.001$ & \\
\hline & Q-BI4 & 0.982 & 0.964 & 0.0357 & & $<0.001$ & \\
\hline \multirow{4}{*}{ Attitude Towards the use of e-learning } & Q-TU1 & 0.781 & 0.610 & 0.3900 & \multirow{4}{*}{0.566} & $<0.001$ & \multirow{4}{*}{0.834} \\
\hline & Q-TU2 & 0.688 & 0.473 & 0.5267 & & $<0.001$ & \\
\hline & Q-TU3 & 0.936 & 0.876 & \begin{tabular}{|l|}
0.1239 \\
\end{tabular} & & $<0.001$ & \\
\hline & Q-TU4 & 0.552 & 0.305 & 0.6953 & & $<0.001$ & \\
\hline
\end{tabular}

Table 4 shows the inter-construct correlation of the variables. PU, PEU, RC, IC, BI, and ATU represent Perceived Usefulness, Perceived Ease of Use, Regulatory Compliance, Implementation Context, Behavioural Intention, and Attitude towards Use. The result shows that the indexes and reliability measurements were within the prescribed ranges, suggesting that all requirements fit the model and met the validity and reliability criteria. The relationships of the hypothesize in Section 3 were also used to check. Compared to the measurement model, both fit indices for the structural model were within the prescribed ranges $(\ddot{\mathrm{y}} 2 / d f=3.81, \mathrm{NFI}=0.958, \mathrm{CFI}=0.934$, TLI $=0.933$, RMSEA $=0.063$, SRMR $=0.052$ ). Table 4 shows the findings with standardized coefficients for the route analysis. It is important to note that a relationship exists between learners' and educators' perceived usefulness and attitude towards adopting virtual learning for learning during the global pandemic of Covid-19 with $\beta=0.271$ and $p<0.001$. 
Table 4. Discriminant Validity of Inter-Construct Correlations

\begin{tabular}{|l|c|c|c|c|c|c|}
\hline Variables & PU & PEU & RC & IC & BI & ATU \\
\hline PU & 0.833 & & & & & \\
\hline PEU & 0.673 & 0.787 & & & & \\
\hline RC & 0.831 & 0.654 & 0.912 & & & \\
\hline IC & 0.377 & 0.578 & 0.455 & 0.605 & & \\
\hline BI & 0.881 & 0.599 & 0.764 & 0.723 & 0.797 & \\
\hline ATU & 0.785 & 0.873 & 0.687 & 0.682 & 0.564 & 0.752 \\
\hline
\end{tabular}

A strong relationship also exists between perceived ease of use and educators' attitude and learners with $\beta=0.268$ and $p<0.001$. Figure 4 shows the regression analysis result for all the constructs. There is significant congruence between educators' attitude and behavioral intention to adopt virtual learning for learning during the global pandemic of Covid-19 $(\beta=0.328, \mathrm{p}<0.001)$. Therefore, we could accept that the results show that RQ1, RQ2, and RQ5 regarding the basic TAM are supported. The result in Table 4 show support for RQ4 and RQ5. Implementation context has a positive effect on attitude to use $(\beta=0.276, p<0.01)$, while Regulatory Compliance $(\beta=$ $0.602, \mathrm{p}<0.001)$ provides empirical support for RQ3 and RQ4. Additionally, a high $\beta$ of the RQ4 indicates a powerful impact of regulatory compliance on the attitude to use virtual learning technology for learning during the Covid-19 lockdown.

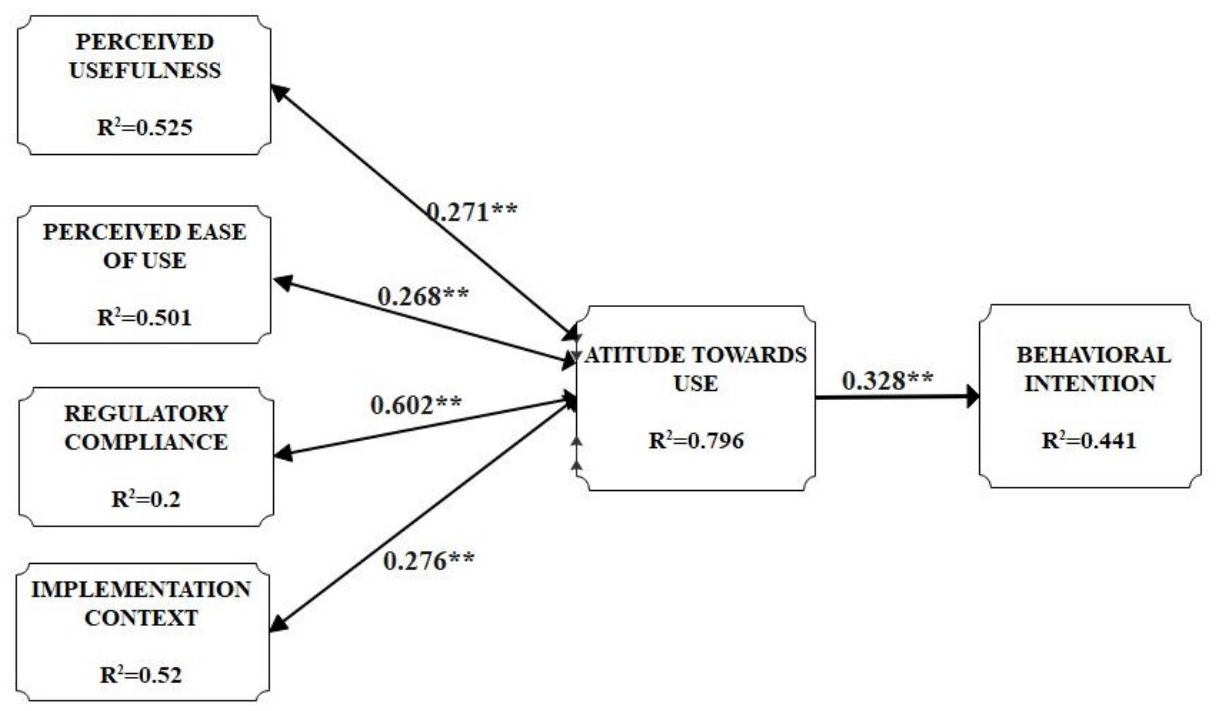

Fig. 4. The regression analysis result

\subsection{Reality of COVID-19 in Africa references}

Figure 5 gives a graphical overview of the top 5 most affected countries in Africa. It will be observed that as at 31st August 2020, South Africa has the highest number 
of reported and confirmed cases $(627,041)$. This is closely followed by Egypt with 98,939 reported and confirmed case, then Nigeria with 54,008 reported and confirmed cases, then Morocco with 62,590 cases and Kenya with 34,201 reported and confirmed cases. Emphasis was laid on reported and confirmed cases because certainly not all cases were reported. In some instance, cases were confirmed after deaths were reported; these were not captured as reported and confirmed cases. Form the figure, the more the cases, the more the deaths recorded and the more the number of recovered cases.

Figure 5 gives a graphical overview of the top 5 most affected countries in Africa. It will be observed that as at 31st August 2020, South Africa has the highest number of reported and confirmed cases $(627,041)$. This is closely followed by Egypt with 98,939 reported and confirmed case, then Nigeria with 54,008 reported and confirmed cases, then Morocco with 62,590 cases and Kenya with 34,201 reported and confirmed cases. Emphasis was laid on reported and confirmed cases because certainly not all cases were reported. In some instance, cases were confirmed after deaths were reported; these were not captured as reported and confirmed cases. Form the figure, the more the cases, the more the deaths recorded and the more the number of recovered cases.

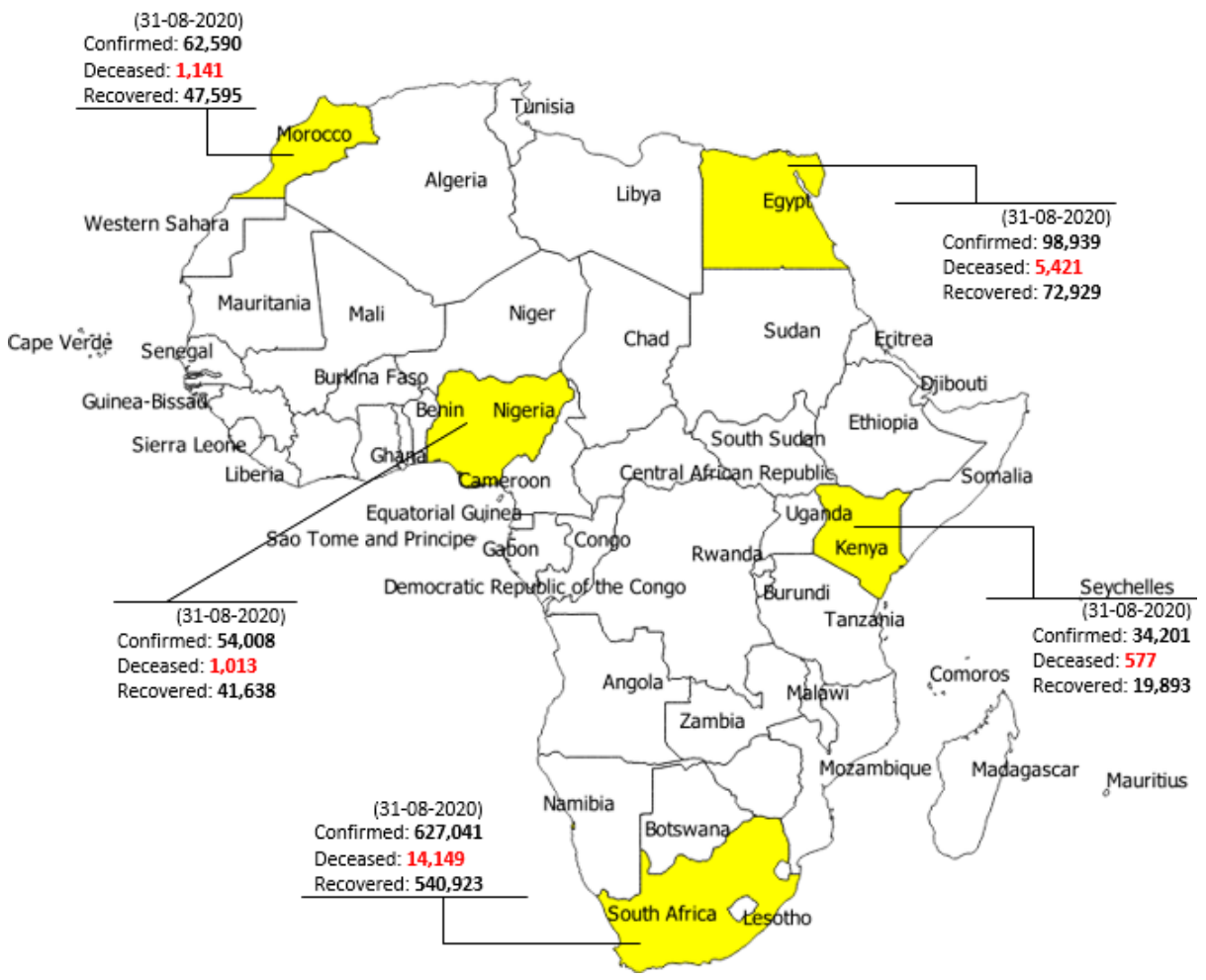

Fig. 5. Top 5 most affected countries in Africa 


\subsection{Discussion}

This study considers the display of virtual learning in the educational sector. Several interactions and social communications always occur in physical teaching and learning, making teaching and learning exciting. The recent coronavirus outbreak, however, has explored the relationship to the extent that during this pandemic outbreak, school owners, Teaching Hospitals, employee trainers and even the government have to consider e-learning an inevitable choice. In this case, via a transmitted medium, information, illustrations, and skills are provided to the degree that virtual communication is now the case. Compulsory physical, social distance control has led to the requisite virtual social interactions and communications. Thus, the school environment is challenged to innovate and promote quality education mediated by the only virtual learning environments' latest technological features. The recent virtual learning stands as the highest level of ICT application the world has ever experienced in the educational sector. The level at which the learners participated actively was a great surprise. Most educators have to personally train themselves overnight to adjust to the new teaching environment was also surprising. Virtual learning technology is one of the main procedures the government adopted to achieve active teaching and learning in our schools and institutions with a possible resemblance and seemly real to physical learning [32] [11].

Feedback polls suggest a high degree of satisfaction from respondents. Trainees were also able to comment on change in morale as redeployment to other specialties created some concern about preparation. In this period of confusion, keeping trainees involved with the specialty is also important. Historically, technological issues have been the most common challenges facing the use of electronic platforms to deliver virtual learning [33] [7]. Most of the studies focused on the negative effects on hospitality and tourism from the perspective of market threats and restrictive purchasing habits on COVID-19 and past (e.g. SARS and MERS) pandemics [34] [35] [36] [37]. We have examined the reason behind the recent urge for virtual learning, resulting from the COVID-19 outbreak. We consider the learners' attitude and education towards e-learning in secondary schools and tertiary institutions in Nigeria. Table 1 shows that many learners were not aware of some of the e-learning platforms before the pandemic outbreak but are now familiar with using most e-learning applications for their studies. Though experimental subjects have to be a little lacking quality in this period, virtual learning has helped reduce expenses in situations where real hardware teaching materials are excessively costly. The reliability of the measurement in Table 3 shows that virtual learning technologies are quickly growing and recognized within education because learners embrace the educational system's distance interactive contexts within a short period. Virtual learning technology has provided a good option for the educational sector in emergencies, where students could not be physically reached. 


\section{Conclusion}

The research addressed in this paper examined virtual learning and immersive technology as an unavoidable pedagogical tool for learning in Africa during the COVID-19 pandemic. The overall study findings were prodigiously optimistic, with learners and educators showing the rate of acceptance of virtual learning for learning during Nationwide Lockdown. It demonstrated how regulatory compliance to stop the spread of coronavirus positively affects educators' and learners' attitudes toward the use of virtual learning. The use of virtual learning technology has seemed unavoidable even between teen-learners and grown-up educators despite the cost, social influence, and the technical know-how attached to technology for learning. The coronavirus outbreak contributes to the growing body of research on technology in Africa. Besides, it substantiates that perceived usefulness influences attitude towards learning using virtual learning for learning in Africa. Social norms seem to have a statistically significant effect on behavioral intention to use, attitude towards the use, perceived ease of use, and perceived usefulness. Social influence affects the way users accept and adopt the technology. The adoption of virtual learning enhances learning during the coronavirus pandemic lockdown; it provides access to learning for all categories of learners anywhere at the same time and create a virtual classroom experience for the learners. The future direction of this study would be the effect of lock-down in sports activities and Military training.

\section{Acknowledgment}

Authors appreciate Landmark University Centre for Research, Innovation and Development for sponsoring the publication of this article.

\section{$7 \quad$ References}

[1] Africa, C. D. C. (2020). COVID-19 daily updates. Africa CDC

[2] Curtis, M. P., \& Jayashankar Reddy, K. A Study on Work from Home, Motivation \& Productivity of Employees in Indian Population during COVID-19 Pandemic.

[3] Ebrahim, S. H., Ahmed, Q. A., Gozzer, E., Schlagenhauf, P., \& Memish, Z. A. (2020). Covid-19 and community mitigation strategies in a pandemic. https://doi.org/10.1136/ bmj.m1066

[4] Baud, D., Giannoni, E., Pomar, L., Qi, X., Nielsen-Saines, K., Musso, D., \& Favre, G. (2020). COVID-19 in pregnant women-Authors' reply. The Lancet Infectious Diseases. https://doi.org/10.1016/s1473-3099(20)30192-4

[5] Perifanou, M., Economides, A. A., \& Tzafilkou, K. (2021). Teachers, Digital Skills Readiness During COVID-19 Pandemic. International Journal of Emerging Technologies in Learning (IJET), 16(8), 238-251. https://doi.org/10.3991/ijet.v16i08.21011

[6] Rudolph, C. W., Allan, B., Clark, M., Hertel, G., Hirschi, A., Kunze, F., ... \& Zacher, H. (2020). Pandemics: Implications for Research and Practice in Industrial and Organizational Psychology. https://doi.org/10.1017/iop.2020.48 
[7] Oktavianto, D. A., Utaya, S., Taryana, D., \& Malang, U. N. (2021). Blended Learning Integrated Fieldwork on Fundamentals of Geology Learning During the Covid-19 Pandemic. International Journal of Emerging Technologies in Learning (IJET), 16(8), 90 104. https://doi.org/10.3991/ijet.v16i07.21213

[8] Swami, V., Frederick, D. A., Aavik, T., Alcalay, L., Allik, J., Anderson, D., ... \& Danel, D. (2010). The attractive female body weight and female body dissatisfaction in 26 countries across 10 world regions: Results of the International Body Project I. Personality and social psychology bulletin, 36(3), 309-325. https://doi.org/10.1177\%2F0146167209359702

[9] LaViola Jr, J. J. (2000). A discussion of cybersickness in virtual environments. $A C M$ Sigchi Bulletin, 32(1), 47-56. https://doi.org/10.1145/333329.333344

[10] Merhi, O., Faugloire, E., Flanagan, M., \& Stoffregen, T. A. (2007). Motion sickness, console video games, and head-mounted displays. Human factors, 49(5), 920-934. https://doi.org/10.1518/001872007x230262

[11] Noah Oluwatobi Akande, Taofeeq Alabi Badmus, Akindele Tosin Akinyinka, Tayo Oladiran Arulogun, "Dataset to Support the Adoption of Social Media and Emerging Technologies for Students' Continuous Engagement" Data-in-Brief, Vol. 31, pp. 1-7. https://doi.org/10.1016/j.dib.2020.105926

[12] Litvinova, T., Andriutsa, N., Movchun, V., \& Federation, R. (2021). Developing Students , Intercultural Communicative Competence Through Online Learning. International Journal of Emerging Technologies in Learning (IJET), 16(8), 162-172. https://doi.org/1 $\underline{0.3991 / \text { ijet.v16i08.18947 }}$

[13] Oladiran Tayo Arulogun, Noah Oluwatobi Akande, Tosin Akinyinka Akindele, Taofeeq Alabi Badmus "Survey Dataset on Open and Distance Learning Students' Intention to use Social Media and Emerging Technologies for Online Facilitation”, Data-in-Brief, Vol. 31, pp. 1-8. https://doi.org/10.1016/j.dib.2020.105929

[14] Ajzen, I. F. M. (Eds.) (1980) Understanding attitudes and predicting social behavior.

[15] Madden, T. J., Ellen, P. S., \& Ajzen, I. (1992). A comparison of the theory of planned behavior and the theory of reasoned action. Personality and social psychology Bulletin, 18(1), 3-9. https://doi.org/10.1177/0146167292181001

[16] Gefen, D., Karahanna, E., \& Straub, D. W. (2003). Trust and TAM in online shopping: An integrated model. MIS Quarterly, 27(1), 51-90. https://doi.org/10.2307/30036519

[17] Diop, E. B., Zhao, S., \& Duy, T. V. (2019). An extension of the technology acceptance model for understanding travelers' adoption of variable message signs. PLoS One, 14(4), e0216007. https://doi.org/10.1371/journal.pone.0216007

[18] Nagovitsyn, R. S., Valeeva, R. A., Osipov, A. Y., Kudryavtsev, M. D., \& Zakharova, L. V. (2021). Upbringing of Student Teachers in Extracurricular Activities in the Context of Distance Learning. International Journal of Emerging Technologies in Learning (IJET), 16(08), 61-76. https://doi.org/10.3991/ijet.v16i08.19103

[19] Zainab, B., Awais Bhatti, M., \& Alshagawi, M. (2017). Factors affecting e-training adoption: an examination of perceived cost, computer self-efficacy, and the technology acceptance model. Behaviour \& Information Technology, 36(12), 1261-1273. https://doi.org/ $\underline{10.1080 / 0144929 x .2017 .1380703}$

[20] Liebenberg, J., Benade, T., \& Ellis, S. (2018). Acceptance of ICT: Applicability of the unified theory of acceptance and use of technology (UTAUT) to South African students. The African Journal of Information Systems, 10(3), 1.

[21] King, W. R., \& He, J. (2006). A meta-analysis of the technology acceptance model. Information \& management, 43(6), 740-755. https://doi.org/10.1016/j.im.2006.05.003

[22] Nubi, O. J., \& Vincent, O. R. (2020). Virtual Learning: A Pedagogical Model for Simulation-Based Learning. In 2020 International Conference in Mathematics, Computer Engi- 
neering and Computer Science (ICMCECS) (pp. 1-6). IEEE. https://doi.org/10.1109/ ICMCECS47690.2020.240895

[23] Kim, D. H., Kim, H. S., Choi, C. W., Kim, E. K., Kim, B. I., \& Choi, J. H. (2012). Risk factors for pulmonary artery hypertension in preterm infants with moderate or severe bronchopulmonary dysplasia. Neonatology, 101(1), 40-46. https://doi.org/10.1159/000327891

[24] Davis, F. D., Bagozzi, R. P., \& Warshaw, P. R. (1992). Extrinsic and intrinsic motivation to use computers in the workplace 1. Journal of applied social psychology, 22(14), 11111132. https://doi.org/10.1111/j.1559-1816.1992.tb00945.x

[25] Chau, T., Maurer, F., \& Melnik, G. (2003, June). Knowledge sharing: Agile methods vs. tayloristic methods. In WET ICE 2003. Proceedings. Twelfth IEEE International Workshops on Enabling Technologies: Infrastructure for Collaborative Enterprises, 2003. (pp. 302-307). IEEE. https://doi.org/10.1109/enabl.2003.1231427

[26] Bagozzi, R. P., Yi, Y., \& Phillips, L. W. (1991). Assessing construct validity in organizational research. Administrative science quarterly, 421-458. https://doi.org/10.2307/ $\underline{2393203}$

[27] Zainab, B., Bhatti, M. A., Pangil, F. B., \& Battour, M. M. (2015). E-training adoption in the Nigerian civil service. European Journal of Training and Development. https://doi.org/ 10.1108/ejtd-11-2014-0077

[28] Adewole-Odeshi, E. (2014). Attitude of students towards E-learning in South-West Nigerian universities: an application of technology acceptance model. Library Philosophy and Practice, $0 \_1$.

[29] Alalwan, A. A., Dwivedi, Y. K., Rana, N. P., \& Algharabat, R. (2018). Examining factors influencing Jordanian customers' intentions and adoption of internet banking: Extending UTAUT2 with risk. Journal of Retailing and Consumer Services, 40, 125-138. https://doi.org/10.1016/j.jretconser.2017.08.026

[30] Chao, C. M. (2019). Factors determining the behavioral intention to use mobile learning: An application and extension of the UTAUT model. Frontiers in psychology, 10, 1652. https://doi.org/10.3389/fpsyg.2019.01652

[31] Shroff, R. H., Deneen, C. C., \& Ng, E. M. (2011). Analysis of the technology acceptance model in examining students' behavioural intention to use an e-portfolio system. Australasian Journal of Educational Technology, 27(4). https://doi.org/10.14742/ajet.940

[32] Firmansyah, R., Putri, D. M., Galih, M., Wicaksono, S., Putri, S. F., Widianto, A. A., Malang, U. N., \& Palil, M. R. (2021). Educational Transformation: An Evaluation of Online Learning Due to COVID-19. International Journal of Emerging Technologies in Learning (IJET), 16(07), 61-76. https://doi.org/10.3991/ijet.v16i07.21201

[33] C Johnson, K Corazzini, R Shaw. Assessing the feasibility of using virtual environments in distance education Knowledge Management \& E-Learning: An International Journal, 2011. pp.5-16. https://doi.org/10.34105/j.kmel.2011.03.002

[34] Joo, H., Maskery, B. A., Berro, A. D., Rotz, L. D., Brown, C. M., \& Lee, Y. K. (2019). Economic impact of the 2015 MERS outbreak on the Republic of Korea's tourismrelated industries, Health Security, 17(2), 100-108. https://doi.org/10.1089/hs.2018.0115

[35] Pine, R., \& McKercher, B. (2004). The impact of SARS on Hong Kong's tourism industry. International Journal of Contemporary Hospitality Management, 16(2), 139-143. https://doi.org/10.1108/09596110410520034

[36] Shin, H., \& Kang, J. (2020). Reducing perceived health risk to attract hotel customers in the COVID-19 pandemic era: Focused on technology innovation for social distancing and cleanliness. International Journal Hospitality Management, 91, 102664. https://doi.org/ $\underline{10.1016 / j . i j h m .2020 .102664}$ 
[37] Yu, J., Lee, K., \& Hyun, S. S. (2021). Understanding the influence of the perceived risk of the coronavirus disease (COVID-19) on the post-traumatic stress disorder and revisit intention of hotel guests. Journal of Hospitality and Tourism Management. https://doi.org/ $\underline{10.1016 / j . j h t m .2021 .01 .010}$

\section{Authors}

Nubi James is with department of Computer Science, Federal University of Agriculture, Abeokuta, Nigeria.

Olufunke Rebecca Vincent is with department of Computer Science, Federal University of Agriculture, Abeokuta, Nigeria.

Noah Oluwatobi Akande is with department of Computer Science, Landmark University, Kwara State, Nigeria.

Ayodeji Samuel Makinde is with department of Computer Science, Edo University, Iyamho, Nigeria.

Article submitted 2021-04-26. Resubmitted 2021-05-25. Final acceptance 2021-05-27. Final version published as submitted by the authors. 